\title{
Will emergency and surgical patients participate in and complete alcohol interventions? A systematic review
}

\author{
Bolette Pedersen ${ }^{1,2^{*}}$, Kristian Oppedal $^{3}$, Lisa Egund ${ }^{4}$ and Hanne Tønnesen ${ }^{1,2}$
}

\begin{abstract}
Background: In the everyday surgical life, staff may experience that patients with Alcohol Use Disorders (AUDs) seem reluctant to participate in alcohol intervention programs. The objective was therefore to assess acceptance of screening and intervention as well as adherence to the intervention program among emergency department (ED) and surgical patients with AUDs.

Methods: A systematic literature search was followed by extraction of acceptance and adherence rates in ED and surgical patients. Numbers needed to screen (NNS) were calculated. Subgroup analyses were carried out based on different study characteristics.

Results: The literature search revealed 33 relevant studies. Of these, 31 were randomized trials, 28 were conducted in EDs and 31 evaluated the effect of brief alcohol intervention. Follow-up was mainly conducted after six and/or twelve months.

Four in five ED patients accepted alcohol screening and two in three accepted participation in intervention. In surgical patients, two in three accepted screening and the intervention acceptance rate was almost 100\%. The adherence rate was above $60 \%$ for up to twelve months in both ED and surgical patients. The NNS to identify one eligible AUD patient and to get one eligible patient to accept participation in alcohol intervention varied from a few up to 70 patients.

The rates did not differ between randomized and non-randomized trials, brief and intensive interventions or validated and self-reported alcohol consumption. Adherence rates were not affected by patients' group allocation and type of follow-up.
\end{abstract}

Conclusions: Most emergency and surgical patients with AUD accept participation in alcohol screening and interventions and complete the intervention program.

\section{Background}

Staff working in emergency or surgical departments will frequently encounter patients with alcohol use disorders (AUDs). These include hazardous drinking exceeding a weekly or daily threshold as well as harmful and dependent drinking [1]. In emergency departments (ED) up to four in ten patients suffer from AUDs [2,3], and AUDs are especially widespread among trauma patients [4]. The frequency of AUD patients in elective surgery varies according to

\footnotetext{
* Correspondence: bped0046@bbh.regionh.dk

${ }^{1}$ WHO Collaborating Centre for Evidence-based Health Promotion in Hospitals and Health Services, Bispebjerg University Hospital, Copenhagen NV, Denmark

Full list of author information is available at the end of the article
}

diagnosis and type of operation; for example are less than one in ten women undergoing hysterectomy AUD patients [5]. On the contrary, in patients undergoing tumor resection of the upper digestive tract up to six in ten suffer from AUDs [6]. Several screening tools have been developed and tested to detect AUDs including CAGE ('Cut down, Annoyed, Guilty, Eye-opener') [7], MAST (Michigan Alcoholism Screening Test) [8], and AUDIT (Alcohol Use Disorder Identification Test) [9].

Patients with AUDs develop more complications following surgery and are more often readmitted to EDs $[10,11]$. Some alcohol intervention programs have proven a positive effect on these outcomes through a reduction of alcohol consumption or abstinence $[12,13]$, but overall

\section{Ciomed Central}


the evidence for alcohol intervention programs in hospitals is unclear [14-16]. Furthermore, staff may expect or experience difficulties with getting ED or surgical patients to participate in alcohol intervention programs $[17,18]$.

This review will therefore assess acceptance of alcohol screening, acceptance of alcohol intervention and adherence to intervention among AUD patients in emergency and surgical departments, as knowledge about these rates are important when planning future alcohol interventions.

\section{Methods}

\section{Criteria for considering studies for this review Types of studies}

Only randomized and controlled clinical trials were included. Studies including consecutive adult elective or acute patients with AUDs treated in a surgical or emergency department were considered. Reviews and other types of secondary literature were excluded. Other exclusion criteria were population or staff interventions and studies conducted in other settings than hospitals.

\section{Types of data}

Papers and abstracts were included if they provided data on definition of AUDs and identification method, numbers/rates regarding acceptance and adherence, and type of alcohol intervention.

\section{Types of methods}

Interventions of interest were all alcohol intervention programs focusing on alcohol reduction or cessation. Interventions could be brief or intensive, including programs with pharmaceutical interventions for alcohol withdrawal and relapse prophylaxis. Control groups were defined as assessment of AUDs only or treatment as usual.

\section{Types of outcome measures}

Screening acceptance rate $=$ Number screened for AUDs/Total patient population;

Intervention acceptance rate $=$ Number participating in intervention/Number of eligible AUD patients fulfilling study inclusion criteria;

Adherence rates $=$ Number of patients at follow-up(s)/ Number of patients accepting intervention.

Numbers needed to screen (NNS) $=1 /$ (number of eligible/total patient population) and $1 /$ (number accepting intervention/total patient population).

\section{Electronic searches and other resources}

The literature search was performed in the following databases: MEDLINE, the Cochrane Central Register of Controlled Trials (CENTRAL), EMBASE and Cinahl (see detailed search strategy for each database in table 1). No time or language restrictions were set. Both full paper articles as well as abstracts were considered. Titles and abstracts were screened to exclude any clearly irrelevant papers. All potentially relevant papers and abstract were then assessed in accordance with the inclusion and exclusion criteria. Two authors ( $\mathrm{BP}$ and $\mathrm{KO}$ ) were responsible for screening and assessment of abstracts and full paper articles.

Reference lists and related articles from the included papers were hand-searched to identify other relevant studies. Additional database searches were conducted in http://www.controlled-trials.com, http://www.clinicaltrials.gov and http://www.centerwatch.com. A third author (LE) was responsible for this part. Any disagreement was solved by consensus involving all authors (BP, KO, LE and HT).

\section{Data abstraction}

The following information was extracted: Type of patients, definition and method(s) used to identify AUDs, total patient population, number screened for AUDs, number of eligible AUD patients, number of eligible AUD patients accepting intervention, type of alcohol intervention, type and time for follow-up visit(s) and number of patients at follow-up.

\section{Data analysis}

Acceptance and adherence rates as well as NNS were calculated for ED and surgical patients respectively. Results are given as median (range).

The following subgroup analyses were carried out comparing randomized clinical trials versus controlled clinical trials, intensive intervention programs versus brief intervention, bio-chemical validation of alcohol consumption versus self-reported consumption only, intervention versus control groups (follow-up rates only) and follow-up by attendance only versus follow-up by contact only (phone, e-mail etc.).

Chi-square tests were used to compare the differences in weighted proportions. A 5\% significance level was accepted.

\section{Results}

\section{Characteristics of included studies}

Thirty-three papers were included in the review [11-13,19-48]; see trial profile in Figure 1. The studies originated from United States (16), United Kingdom (6), Spain (3), Australia (2), Sweden (2), Denmark (1), Finland (1), Germany (1) and Switzerland (1). The trials were published 1988 to 2010.

The majority of the studies (31) were randomized trials, 28 were conducted in EDs and 31 evaluated the effect of brief alcohol interventions. Type of follow-up varied between the studies; in 15 studies patients were contacted by phone and/or mail and in eight studies the patients had 


\section{Table 1 Search strategy for the electronic databases}

MEDLINE search strategy
1. "Alcohol-Related Disorders"[Mesh] OR "Alcohol Drinking"[Mesh] OR
"Alcoholism"[Mesh] OR alcohol abuse OR alcohol use OR alcohol disorder
OR alcohol consumption OR alcohol intake OR alcohol behaviour OR
hazardous drinking OR harmful drinking OR alcohol dependence OR risky
drinking
2. "Temperance"[Mesh] OR alcohol intervention OR alcohol education OR
alcohol program OR alcohol brief intervention OR alcohol reduction OR
alcohol cessation OR alcohol withdrawal OR alcohol abstinence
3. "Emergency Service, Hospital"[Mesh] OR "Wounds and Injuries"[Mesh]
OR "Surgical Procedures, Operative"[Mesh] OR surgical treatment OR
surgical patient OR trauma treatment OR trauma patient OR emergency
treatment OR emergency patient
4. \#1 AND \#2 AND \#3 (limits: Randomized controlled trial, controlled
clinical trial; adults)

clinical trial; adults)

\section{EMBASE search strategy}

1. exp alcohol abuse/OR alcohol consumption/OR drinking behaviour/OR alcoholism/

2. exp alcohol abstinence/OR alcohol withdrawal/OR patient counselling/

3. exp emergency health service/OR emergency care/OR emergency

surgery/OR emergency patient/OR emergency ward/OR emergency

treatment/OR surgical ward/OR surgical patient/OR injury/OR surgery/

4. exp intervention study/OR randomised controlled trial/OR controlled

clinical trial/OR randomisation/OR clinical trial

5. \#1 AND \#2 AND \#3 AND \#4
The Cochrane Central Register of Controlled Trials (CENTRAL)

search strategy

1. "Alcohol-Related Disorders"[Mesh] OR "Alcohol Drinking"[Mesh] OR "Alcoholism"[Mesh] OR alcohol abuse OR alcohol use OR alcohol disorder OR alcohol consumption OR alcohol intake OR alcohol behaviour OR hazardous drinking OR harmful drinking OR alcohol dependence OR risky drinking

2. "Temperance"[Mesh] OR alcohol intervention OR alcohol education OR alcohol program OR alcohol brief intervention OR alcohol reduction OR alcohol cessation OR alcohol withdrawal OR alcohol abstinence

3. "Emergency Service, Hospital"[Mesh] OR "Wounds and Injuries"[Mesh] OR "Surgical Procedures, Operative"[Mesh] OR surgical treatment OR surgical patient OR trauma treatment OR trauma patient OR emergency treatment OR emergency patient

4. \#1 AND \#2 AND \#3

\section{Cinahl search strategy}

1. Alcohol-Related Disorder+ OR alcohol Drinking OR alcoholism OR alcohol abuse OR alcohol use OR alcohol disorder OR alcohol

consumption OR alcohol intake OR alcohol behaviour OR hazardous drinking OR harmful drinking OR alcohol dependence

2. Temperance $O R$ alcohol intervention $O R$ alcohol education $O R$ alcohol program OR brief intervention OR reduction OR cessation OR withdrawal OR abstinence

3. Emergency health service OR emergency care OR emergency surgery OR emergency patient OR emergency ward OR emergency treatment OR surgical ward OR surgical patient OR injury OR surgery

4. \#1 AND \#2 AND \#3

Search conducted $17^{\text {th }}$ of March 2010, updated $25^{\text {th }}$ of November 2010

to attend follow-up. The remaining studies used a combination of the two or type of follow-up was not reported or performed. Follow-up was conducted after one month in two studies and after three months in twelve studies. Seventeen studies had follow-up after six and twelve months. Twenty studies included more than one followup visit. In 16 studies alcohol consumption was biochemically validated. Characteristics of the included studies are presented in table S2 (see additional file 1: Table S2 Characteristics of 33 included studies involving ED or surgical patients).

\section{Acceptance and retention rates Emergency department patients}

In 18 of 28 studies the total patient population was given, in which the median size was 5,640 ranging from 697 to 32,965 patients. Twenty-six studies reported the number of screened patients. Eighteen studies presented both numbers, and their screening acceptance rate was $83 \%$ in median (range 31-98\%); see Figure 2.

The number of patients accepting intervention was reported in all 28 studies; however, not all had information on number of eligible AUD patients. In the 23 studies that reported both, the acceptance rate for intervention among the eligible patients was $67 \%$ (21-96\%); see Figure 3.

All but one trial [42] conducted one or more follow-up visits. Only one study [28] had a one-month follow-up visit and the adherence rate was $62 \%$. The adherence rate after three months was $67 \%$ (54-96\%) based on ten studies
$[19,20,22,27,28,35,36,39,40,48]$, after six months $72 \%(45-$ $89 \%)$ based on 15 studies [11,23-25,27,29,30,33,36-38, $41,44,47,48]$ and $67 \%$ (27-92\%) after twelve months based on 15 studies [11,23-27,29,30,33,34,37,41,44-46].

NNS to identify one eligible AUD patient was seven (232) based on 17 studies [11,19-22,26-30,35,37,39-41,44,47] and NNS to get one eligible AUD patient to accept intervention was ten (4-70) based on 18 studies [11,19-22, 26-30,35,37,39-41,44,46,47].

\section{Surgical patients}

In two $[12,31]$ of five studies the total patient population was given (529 and 3,783 patients respectively) as well as the number of screened patients. The screening acceptance rate in those two studies was 65\% (47-83\%); see figure 2 .

The number of eligible AUD patients and number of patients accepting intervention was reported in all five studies; the acceptance rate for intervention among the eligible patients was 99\% (54-100\%); see figure 3 .

The adherence rate after one month was $83 \%$ in the only study [13] that reported this number. The adherence rate after three months was 73\% (53-92\%) based on two studies $[31,43]$, after six months $85 \%(82-88 \%)$ based on two studies [12,32] and 75\% (69-81\%) after twelve months based on two studies $[31,43]$.

NNS to identify one eligible AUD patient was nine (3-15) based on two studies [12,31], and NNS to get one eligible AUD patient to accept intervention was 15 (3-28) based on the same two studies. 


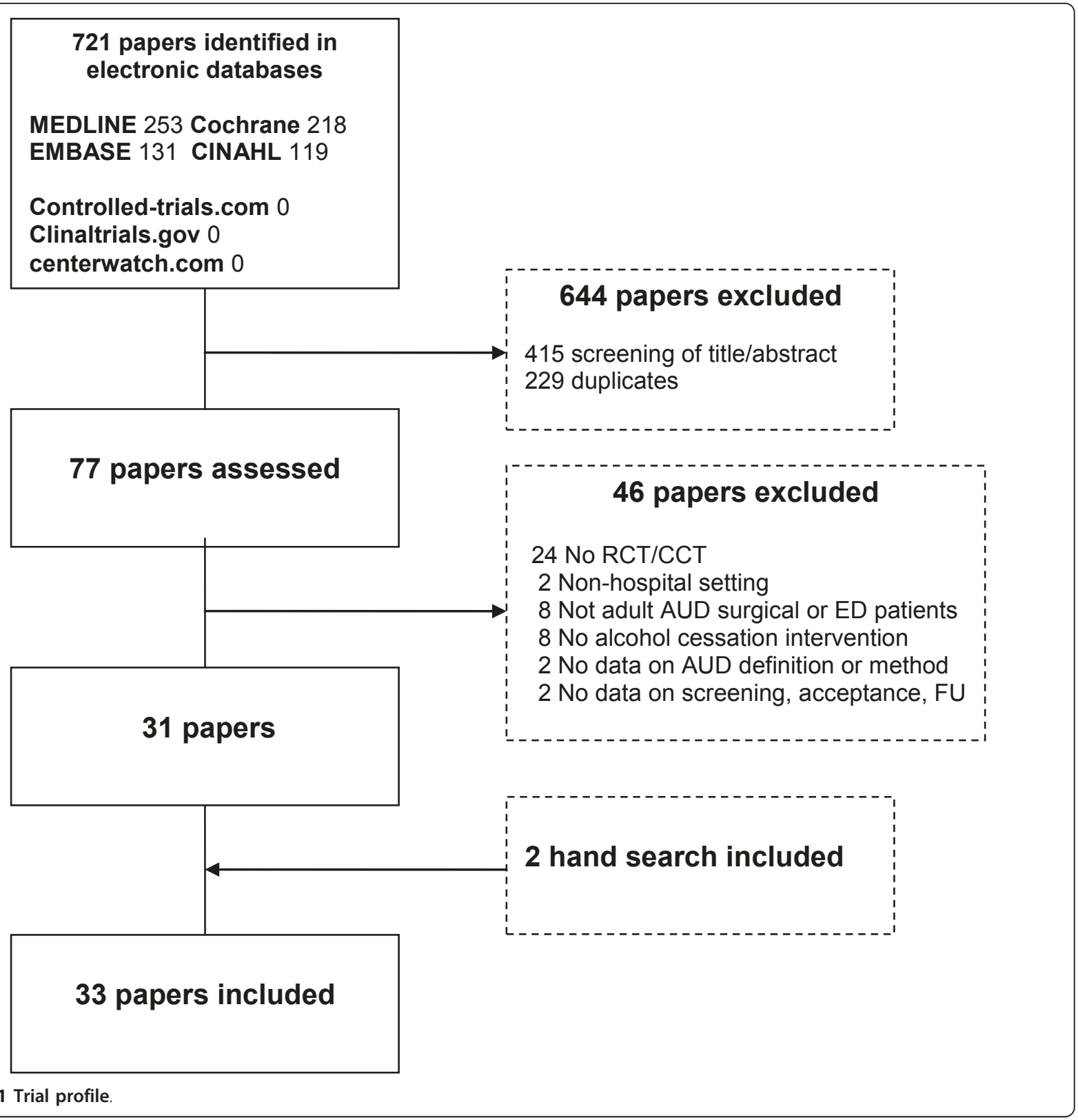

\section{Subgroup analyses}

The results showed that neither type of study, type of intervention nor validation of alcohol consumption affected the acceptance and adherence rates. Furthermore, the adherence rates were not affected by patients' group allocation or type of follow-up.

\section{Discussion}

This review showed high acceptance rates for alcohol screening and intervention as well as adherence to intervention among emergency and surgical patients with AUDs. Four in five ED patients accepted alcohol screening compared to two in three surgical patients, whereas the intervention acceptance rate was to two out of three in ED patients compared to almost $100 \%$ among surgical patients. Though, as only a minority of the studies was conducted among surgical patients, no conclusions can be made regarding possible differences in emergency and surgical patients' acceptance of alcohol screening and interventions. Adherence to the alcohol intervention programs was above $60 \%$ for up to twelve months in both ED and surgical patients. Overall, the numbers needed to screen to identify one eligible AUD patient and to get one eligible patient to accept intervention varied from a few up to 70 patients.

Acceptance of alcohol screening among AUD patients in intervention trials was not reduced compared to 

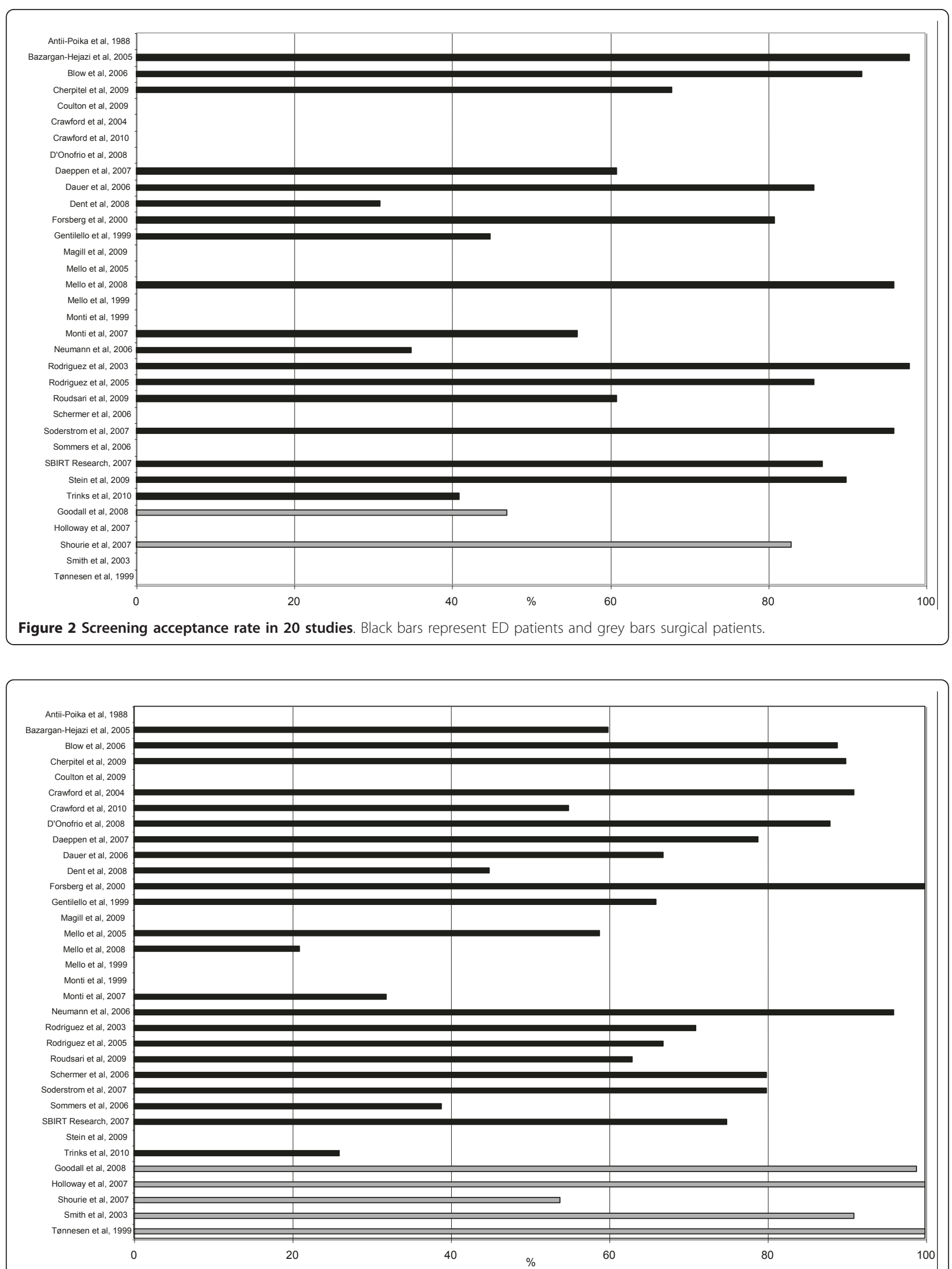

Figure $\mathbf{3}$ Intervention acceptance rate in $\mathbf{2 8}$ studies. Black bars represent ED patients and grey bars surgical patients. 
studies performing screening exclusively [49-52], despite the fact that the consequences of being identified with an AUD in an intervention trial can be more comprehensive regarding study participation and possible changes in alcohol consumption.

The NNS are important when planning future interventions. Here the NNS to identify one AUD patient is not different from that described in primary care [53]. However, the NNS for acceptance of alcohol intervention is up to four times higher in primary care. This indicates a larger potential for conducting alcohol interventions in hospital settings.

In addition, the acceptance and adherence rates are comparable to those in smoking cessation intervention studies conducted in similar patient groups [54-57].

We were not able to show that any of the study characteristics facilitated or hindered acceptance or adherence, but the rates were probably influenced by multiple other factors for example patients sex, age and lifestyle [58].

\section{Bias and limitations}

The weaknesses of this review are closely related to the weaknesses of the individual studies. In general, the included studies were heterogeneous. The intervention and primary outcomes differed from study to study. Screening methods used for detecting AUDs varied notably between the studies from blood tests to interviews and different questionnaires. The included questionnaires mainly focus on alcohol abuse and dependency and have mostly been developed in non-surgical settings [10]. These questionnaires may therefore not be useful for detecting a current hazardous alcohol intake in surgical patients, which is the most clinical relevant outcome [59]. Also, in emergency departments there does not appear to be a gold standard tool for screening for AUDs [60].

Moreover, the studies used different questionnaires and in the same questionnaires different cut-of points were sometimes applied. As a result a patient identified with AUD in one study would not necessarily be identified or included in another study. This could affect the NNS. In addition, differences in other inclusion and exclusion criteria between the studies could also influence the NNS.

Many studies had not reported the total patient population and number of patients accepting screening and alcohol intervention. Also, numbers of patients available for follow-up were not given in a few studies. Missing data from several studies may have affected the acceptance and adherence rates as well as the value of the subgroup analyses, where data in many cases was limited. Furthermore, as almost all studies described randomized trials and brief interventions comparisons among the few studies having other characteristics may not be valid.

\section{Generalization}

No comparable systematic or narrative reviews were found. Other studies on patient opinions and experiences found that patients in EDs were positive towards alcohol screening including blood tests $[61,62]$. Also, in interviews with AUD patients following intervention they described the ED as an appropriate setting [63]. A recent study among acute surgical patients with AUDs sustained that alcohol intervention is relevant in relation to surgery [64].

Though generalization of the results should be considered carefully, the ED patients and patients undergoing surgery do not seem to form a major barrier for introducing alcohol screening and intervention programs. The high acceptance and adherence rate may also reflect staff effort and compliance to research protocol. Compared to project staff, the clinical staff may experience other barriers for alcohol screening and intervention such as missing knowledge and training as well as lack of time, appropriateness of setting and implementation into daily routines [65-67]. These barriers may, however, be overcome by prioritizing the area through professional teaching and training as well as using lessons learned regarding appropriate setting and resources.

The clinical routines differ from study settings in several ways. In general, projects and studies benefit from a very professional approach from trained and experienced staff, who are also highly dedicated to screen patients, intervene and follow-up. Study settings have also been tailored to meet the requirements for completing the project parts. In this way, several of the barriers above are overcome.

\section{Perspectives}

A background WHO-paper concluded that there are no technical barriers for handling alcohol intervention as well as other hospital-based health promoting activities in the DRG-system [68]. Furthermore, a simple model for documentation of patient need for alcohol intervention and the related health promotion activity was shown to be useful, applicable and understandable when evaluated internationally in clinical settings [69]. These international tools are an integrated part of WHO standards and they all fit into the hospitals' quality management [70].

\section{Conclusions}

In conclusion, this review showed that most emergency and surgical patients with AUDs accept participation in alcohol screening and interventions and complete the intervention program.

\section{Additional material}

Additional file 1: Table S2 - Characteristics of 33 included studies involving ED or surgical patients. 


\section{Abbreviations}

AUD: Alcohol Use Disorder; ED: Emergency Department; NNS: Numbers needed to screen

\author{
Acknowledgements \\ None \\ Funding \\ No funding was received for carrying out this study.
}

\section{Author details}

${ }^{1}$ WHO Collaborating Centre for Evidence-based Health Promotion in Hospitals and Health Services, Bispebjerg University Hospital, Copenhagen NV, Denmark. ${ }^{2}$ Clinical Alcohol Research, Faculty of Medicine, Lund University, Sweden. ${ }^{3}$ Alcohol and Drug Research Western Norway, Stavanger University Hospital, Stavanger, Research Unit for General Practice, Uni Health, Bergen, Norway. ${ }^{4}$ Orthopaedic Department, Skane University Hospital Malmö, Lund University, Sweden.

\section{Authors' contributions}

Two authors (BP and $\mathrm{KO}$ ) independently screened titles and abstracts from the identified papers, and articles with clearly irrelevant content were excluded. The same two authors independently assessed all other articles according to the inclusion criteria. A third author (LE) performed the additional search in reference lists, databases etc. Any disagreement was solved by consensus involving all authors (BP, KO, LE and HT). All authors read and approved the final manuscript.

\section{Competing interests}

The authors declare that they have no competing interests.

Received: 14 January 2011 Accepted: 23 September 2011 Published: 23 September 2011

\section{References}

1. World Health Organization: WHO Lexicon of alcohol and drug terms 2010.

2. Neuner B, Miller $P$, Wang KK, Weiss-Gerlach $E$, Neumann $T$, Schoenfeld $H$, Haas N, Mueller JM, Wernecke KD, Mann K, et al: Socioeconomic factors, hazardous alcohol consumption, and smoking in patients with minor trauma in an inner-city emergency department. J Emerg Med 2010, 39(5):554-560.

3. Alderete $E$, Bianchini P: Alcohol consumption in the emergency room. Medicina (B Aires) 2008, 68(1):31-36.

4. Charalambous MP: Alcohol and the accident and emergency department: a current review. Alcohol Alcohol 2002, 37:307-312.

5. Felding $C$, Jensen $L M$, Tønnesen $H$ : Influence of alcohol intake on postoperative morbidity after hysterectomy. Am J Obstet Gynecol 1992, 166:667-670.

6. Spies CD, Nordmann A, Brummer G, Marks C, Conrad C, Berger G, Runkel N, Neumann T, Muller $\mathrm{C}$, Rommelspacher $\mathrm{H}$, et al: Intensive care unit stay is prolonged in chronic alcoholic men following tumor resection of the upper digestive tract. Acta Anaesthesiol Scand 1996, 40:649-656.

7. Mayfield D, McLeod G, Hall P: The CAGE questionnaire: validation of a new alcoholism screening instrument. Am J Psychiatry 1974 131:1121-1123.

8. Selzer ML: The Michigan alcoholism screening test: the quest for a new diagnostic instrument. Am J Psychiatry 1971, 127:1653-1658.

9. Saunders JB, Aasland OG, Babor TF, de IF Jr, Grant M: Development of the Alcohol Use Disorders Identification Test (AUDIT): WHO Collaborative Project on Early Detection of Persons with Harmful Alcohol Consumption-II. Addiction 1993, 88:791-804

10. Tønnesen H, Nielsen PR, Lauritzen JB, Møller AM: Smoking and alcohol intervention before surgery: evidence for best practice. $\mathrm{Br} J$ Anaesth 2009, 102(3):297-306.

11. Neumann T, Neuner B, Weiss-Gerlach E, Tonnesen H, Gentilello LM, Wernecke KD, Schmidt K, Schroder T, Wauer H, Heinz A, et al: The effect of computerized tailored brief advice on at-risk drinking in subcritically injured trauma patients. J Trauma 2006, 61:805-814

12. Shourie S, Conigrave KM, Proude EM, Ward JE, Wutzke SE, Haber PS: The effectiveness of a tailored intervention for excessive alcohol consumption prior to elective surgery. Alcohol Alcohol 2006, 41:643-649.
13. Tønnesen H, Rosenberg J, Nielsen HJ, Rasmussen V, Hauge C, Pedersen IK, Kehlet $\mathrm{H}$ : Effect of preoperative abstinence on poor postoperative outcome in alcohol misusers: randomised controlled trial. BMJ 1999, 318:1311-1316.

14. Emmen MJ, Schippers GM, Bleijenberg G, Wollersheim H: Effectiveness of opportunistic brief interventions for problem drinking in a general hospital setting: systematic review. BMJ 2004, 328:318.

15. McQueen J, Allan L, Mains D, Coupar F: Brief interventions for heavy alcohol users admitted to general hospital wards. Cochrane Database Syst Review 2009, 8(3):CD005191.

16. Oppedal K, Møller AM, Tønnesen H: Preoperative alcohol cessation intervention for postoperative complications and alcohol use disorders. Cochrane Database Syst Review: Protocols 2010, CD00843.

17. Hungerford DW, Pollock DA: Emergency department services for patients with alcohol problems: research directions. Acad Emerg Med 2003, 10:79-84

18. Bendtsen P, Holmqvist M, Johansson K: Implementation of computerized alcohol screening and advice in an emergency department-a nursing staff perspective. Accid Emerg Nurs 2007, 15:3-9.

19. Academic-ED-SBIRT-Research-Collaborative: The impact of screening, brief intervention, and referral for treatment on emergency department patients' alcohol use. Ann Emerg Med 2007, 50:699-710, 710.

20. Bazargan-Hejazi S, Bing E, Bazargan M, Der-Martirosian C, Hardin E, Bernstein J, Bernstein E: Evaluation of a brief intervention in an inner-city emergency department. Ann Emerg Med 2005, 46:67-76.

21. Blow FC, Barry KL, Walton MA, Maio RF, Chermack ST, Bingham CR, Ignacio RV, Strecher VJ: The efficacy of two brief intervention strategies among injured, at-risk drinkers in the emergency department: Impact of tailored messaging and brief advice. J Stud Alcohol 2006, 67(4):568-578.

22. Cherpitel CJ, Moskalewicz J, Swiatkiewicz G, Ye Y, Bond J: Screening, brief intervention, and referral to treatment (SBIRT) in a Polish emergency department: three-month outcomes of a randomized, controlled clinical trial. J Stud Alcohol Drugs 2009, 70:982-990.

23. Coulton S, Perryman K, Bland M, Cassidy P, Crawford M, Deluca P, Drummond C, Gilvarry E, Godfrey C, Heather N, et al: Screening and brief interventions for hazardous alcohol use in accident and emergency departments: a randomised controlled trial protocol. BMC Health Serv Res 2009, 9:114.

24. Crawford MJ, Patton R, Touquet R, Drummond C, Byford S, Barrett B, Reece B, Brown A, Henry JA: Screening and referral for brief intervention of alcohol-misusing patients in an emergency department: a pragmatic randomised controlled trial. Lancet 2004, 364:1334-1339.

25. D'Onofrio G, Pantalon MV, Degutis LC, Fiellin DA, Busch SH, Chawarski MC Owens PH, O'Connor PG: Brief intervention for hazardous and harmful drinkers in the emergency department. Ann Emerg Med 2008, 51:742-750.

26. Daeppen JB, Gaume J, Bady P, Yersin B, Calmes JM, Givel JC, Gmel G: Brief alcohol intervention and alcohol assessment do not influence alcohol use in injured patients treated in the emergency department: a randomized controlled clinical trial. Addiction 2007, 102:1224-1233.

27. Dauer AR, Rubio ES, Coris ME, Valls JM: Brief intervention in alcoholpositive traffic casualties: is it worth the effort? Alcohol Alcohol 2006, 41:76-83.

28. Dent AW, Weiland TJ, Phillips GA, Lee NK: Opportunistic screening and clinician-delivered brief intervention for high-risk alcohol use among emergency department attendees: a randomized controlled trial. Emerg Med Australas 2008, 20:121-128.

29. Forsberg L, Ekman S, Halldin J, Ronnberg S: Brief interventions for risk consumption of alcohol at an emergency surgical ward. Addict Behav 2000, 25:471-475.

30. Gentilello LM, Rivara FP, Donovan DM, Jurkovich GJ, Daranciang E, Dunn CW, Villaveces A, Copass M, Ries RR: Alcohol interventions in a trauma center as a means of reducing the risk of injury recurrence. Ann Surg 1999, 230:473-480.

31. Goodall CA, Ayoub AF, Crawford A, Smith I, Bowman A, Koppel D, Gilchrist G: Nurse-delivered brief interventions for hazardous drinkers with alcohol-related facial trauma: a prospective randomised controlled trial. Br J Oral Maxillofac Surg 2008, 46:96-101.

32. Holloway AS, Watson HE, Arthur AJ, Starr G, McFadyen AK, McIntosh J: The effect of brief interventions on alcohol consumption among heavy drinkers in a general hospital setting. Addiction 2007, 102:1762-1770.

33. Magill M, Barnett NP, Apodaca TR, Rohsenow DJ, Monti PM: The role of marijuana use in brief motivational intervention with young adult 
drinkers treated in an emergency department. J Stud Alcohol Drugs 2009, 70:409-413.

34. Mello MJ, Nirenberg TD, Longabaugh R, Woolard R, Minugh A, Becker B, Baird J, Stein L: Emergency department brief motivational interventions for alcohol with motor vehicle crash patients. Ann Emerg Med 2005, 45:620-625.

35. Mello MJ, Longabaugh R, Baird J, Nirenberg T, Woolard R: DIAL: a telephone brief intervention for high-risk alcohol use with injured emergency department patients. Ann Emerg Med 2008, 51:755-764.

36. Monti PM, Colby SM, Barnett NP, Spirito A, Rohsenow DJ, Myers M, Woolard R, Lewander W: Brief intervention for harm reduction with alcohol-positive older adolescents in a hospital emergency department. J Consult Clin Psychol 1999, 67:989-994.

37. Monti PM, Barnett NP, Colby SM, Gwaltney CJ, Spirito A, Rohsenow DJ, Woolard R: Motivational interviewing versus feedback only in emergency care for young adult problem drinking. Addiction 2007, 102:1234-1243.

38. Antti-Poika I, Karaharju E, Roine R, Salaspuro M: Intervention of heavy drinking-a prospective and controlled study of 438 consecutive injured male patients. Alcohol Alcohol 1988, 23:115-121.

39. Rodríquez MA, Santamarina RE, Martinez G, Torralba NL, Escayola CM, Marti VJ, Plasencia TA: Early identification and brief intervention in alcohol-related traffic casualties: Preliminary results. Adicciones 2003, 15:191-202.

40. Rodríguez MA, Santamariña E, Torralba L, Escayola M, Martí J, Plasència A: [Short-term effectiveness of brief interventions in alcohol-positive traffic casualties]. Gaceta sanitaria/S E S P A S 2005, 19:45-49.

41. Roudsari B, Caetano R, Frankowski R, Field C: Do minority or white patients respond to brief alcohol intervention in trauma centers? A randomized trial. Ann Emerg Med 2009, 54:285-293.

42. Schermer CR, Moyers TB, Miller WR, Bloomfield LA: Trauma center brief interventions for alcohol disorders decrease subsequent driving under the influence arrests. J Trauma 2006, 60:29-34.

43. Smith AJ, Hodgson RJ, Bridgeman K, Shepherd JP: A randomized controlled trial of a brief intervention after alcohol-related facial injury. Addiction 2003, 98:43-52.

44. Soderstrom CA, DiClemente CC, Dischinger PC, Hebel JR, McDuff DR, Auman KM, Kufera JA: A controlled trial of brief intervention versus brief advice for at-risk drinking trauma center patients. J Trauma 2007, 62:1102-1112.

45. Sommers MS, Dyehous JM, Howe SR, Fleming M, Fargo JD, Schafer JC: Effectiveness of brief interventions after alcohol-related vehicular injury: a randomized controlled trial. J Trauma 2006, 61:523-533.

46. Stein LA, Minugh PA, Longabaugh R, Wirtz P, Baird J, Nirenberg TD, Woolard RF, Carty K, Lee C, Mello M, et al: Readiness to change as a mediator of the effect of a brief motivational intervention on posttreatment alcohol-related consequences of injured emergency department hazardous drinkers. Psychol Addict Behav 2009, 23:185-195.

47. Trinks A, Festin K, Bendtsen P, Nilsen P: Reach and effectiveness of a computer-based alcohol intervention in a Swedish emergency room. Int Emerg Nurs 2010, 18:138-146.

48. Crawford MJ, Csipke E, Brown A, Reid S, Nilsen K, Redhead J, Touquet R: The effect of referral for brief intervention for alcohol misuse on repetition of deliberate self-harm: an exploratory randomized controlled trial. Psychol Med 2010, 40:1821-1828.

49. Schermer CR, Bloomfield LA, Lu SW, Demarest GB: Trauma patient willingness to participate in alcohol screening and intervention. $J$ Trauma 2003, 54(4):701-706.

50. Nilsen $P$, Holmqvist $M$, Nordqvist $C$, Bendtsen P: Linking drinking to injury-causal attribution of injury to alcohol intake among patients in a Swedish emergency room. Int I Inj Contr Saf Promot 2007, 14(2):93-102.

51. Poon A, Owen J, Gijsbers AJ: Identification of at-risk drinkers in an orthopaedic inpatient population. Aust N Z J Surg 1994, 64(11):775-779.

52. Shourie S, Conigrave KM, Proude EM, Ward JE, Wutzke SE, Haber PS: Preoperative screening for excessive alcohol consumption among patients scheduled for elective surgery. Drug Alcohol Rev 2007, 26(2):119-125.

53. Beich A, Thorsen T, Rollnick S: Screening in brief intervention trials targeting excessive drinkers in general practice: systematic review and meta-analysis. BMJ 2003, 327:536-542.

54. Richman PB, Dinowitz S, Nashed AH, Eskin B, Sylvan E, Allegra C, Allegra J, Mandell $\mathrm{M}$ : The emergency department as a potential site for smoking cessation intervention: a randomized, controlled trial. Acad Emerg Med 2000, 7(4):348-353.

55. Thomsen T, Villebro NM, Møller AM: Interventions for preoperative smoking cessation. Cochrane Database Syst Rev 2010, 7(7):CD002294.

56. Lindström D, Azodi OS, Wladis A, Tønnesen $\mathrm{H}$, Linder $\mathrm{S}$, Nasell $\mathrm{H}$, Ponzer $\mathrm{S}$, Adami J: Effects of a perioperative smoking cessation intervention on postoperative complications: a randomized trial. Ann Surg 2008, 248:739-745.

57. Møller AM, Villebro N, Pedersen T, Tønnesen H: Effect of preoperative smoking intervention on postoperative complications: a randomised clinical trial. Lancet 2002, 359:114-117.

58. Aalto $\mathrm{M}$, Sillanaukee P: Compliance rate and associated factors for entering an alcohol brief intervention treatment programme. Alcohol Alcohol 2000, 35:372-376.

59. Spies $\mathrm{C}$, Tonnesen H, Andreasson S, Helander A, Conigrave K: Perioperative morbidity and mortality in chronic alcoholic patients. Alcohol Clin Exp Res 2001, 25:164S-170S.

60. Jones LA: Systematic review of alcohol screening tools for use in the emergency department. Emerg Med J 2011, 28:182-191.

61. Csipke E, Touquet R, Patel T, Franklin J, Brown A, Holloway P, Batrick N, Crawford MJ: Use of blood alcohol concentration in resuscitation room patients. Emerg Med J 2007, 24(8):535-538.

62. Karlsson A, Bendtsen P: Acceptability of a computerized alcohol screening and advice routine in an emergency department setting-a patient perspective. Addict Behav 2005, 30(4):767-776.

63. Helmkamp JC, Hungerford DW, Williams JM, Manley WG, Furbee PM, Horn KA, Pollock DA: Screening and brief intervention for alcohol problems among college students treated in a university hospital emergency department. J Am Coll Health 2003, 52(1):7-16.

64. Pedersen B, Alva-Jorgensen P, Raffing R, Tonnesen H: Fractures and alcohol abuse - patient opinion of alcohol intervention. Open Orthop J 2011, 5:7-12.

65. Nordqvist $C$, Johansson $K$, Lindqvist $K$, Bendtsen P: Attitude changes among emergency department triage staff after conducting routine alcohol screening. Addict Behav 2006, 31:191-202.

66. Danielsson PE, Rivara FP, Gentilello LM, Maier RV: Reasons why trauma surgeons fail to screen for alcohol problems. Arch Surg 1999, 134:564-568.

67. Graham DM, Maio RF, Blow FC, Hill EM: Emergency physician attitudes concerning intervention for alcohol abuse/dependence delivered in the emergency department: a brief report. J Addict Dis 2000, 19:45-53.

68. Groene O, Tønnesen $\mathrm{H}$ : Reimbursing health promotion services in hospitals through diagnosis related groups. WHO-Collaborating Centre for Evidence-Based Health Promotion in Hospitals and Health Services; 2005.

69. Tønnesen H, Christensen ME, Groene O, O'Riordan A, Simonelli F, Suurorg L, Morris D, Vibe P, Himel S, Hansen PE: An evaluation of a model for the systematic documentation of hospital based health promotion activities: results from a multicentre study. BMC Health Serv Res 2007, 7:145.

70. Groene O, Alonso J, Klazinga N: Development and validation of the WHO self-assessment tool for health promotion in hospitals: results of a study in 38 hospitals in eight countries. Health Promot Int 2010, 25:221-229.

\section{Pre-publication history}

The pre-publication history for this paper can be accessed here: http://www.biomedcentral.com/1471-2482/11/26/prepub

doi:10.1186/1471-2482-11-26

Cite this article as: Pedersen et al:: Will emergency and surgical patients participate in and complete alcohol interventions? A systematic review. BMC Surgery 2011 11:26. 